\title{
DESIGN AND FABRICATION OF REPROMASTER DYEING MACHINE
}

\author{
Orelaja $\mathbf{O} . \mathbf{A}^{1^{*}}$ \\ ${ }^{1}$ Department of Mechanical Engineering, \\ Moshood Abiola Polytechnic, \\ Abeokuta, Ogun State.
}

\author{
Lasisi L. $\mathrm{A}^{2}$ \\ ${ }^{2}$ Department of Art and Industrial Design \\ Moshood Abiola Polytechnic, \\ Abeokuta, Ogun State.
}

\author{
Abiodun O. $\mathbf{I}^{3}$ \\ ${ }^{3}$ Department of Mechanical Engineering, \\ Moshood Abiola Polytechnic, \\ Abeokuta, Ogun State.
}

Article DOI: https://doi.org/10.36713/epra5922

\begin{abstract}
Dyeing is a process of complete colouration of textiles, and this can be achieved by the type and the extent of pretreatment imputed to produce an excellent absorbency and whiteness. Quality dyeing depends on factors such as pH, form of textile, type of fibre, formulation of dyeing recipe, initial preparation of dye solution, liquor mixture ratio, and selection of machinery mixing speed. This research work illustrates basic design and fabrication concepts of repromaster dyeing machine and also to achieve effective implementation of the ideal technology of dyeing. This machine was designed and fabricated to carry out textile dyeing for mass production. Although selection of machine depends on type of process to be carried out, which are batch, semi-continuous or continuous dyeing process. This repromaster dyeing is a continous process machine with an excellent dye output, it is faster, require less skill to operate and cost effective. This research work concept provides some firsthand information on some basic dyeing processes.
\end{abstract}

KEYWORDS: Repromaster, machine, dyeing, working principle, continuous, fibre, colouration.

\subsection{INTRODUCTION}

Dyeing can be describe as the application of dyes or pigments on textile or fabric materials such as fibers, yarns, and fabrics with the aim of achieving the desired color within a specified time. Dyeing is often done in a special solution containing dyes and particular chemical material. Dye molecules are attracted to the fiber by absorption, diffusion, or bonding with temperature and time as controlling factors. Bond between dye molecule and fiber may be strong or weak, depending on the type of dye used. Dyeing and printing are different applications; in printing, color is applied to a localized or certain area with desired patterns, while in dyeing, it is applied to the entire textile.

\subsection{LITERATURE REVIEW}

The primary source of dye, historically, is from animals or plants. As far back as the middle of 19th century, humans have produced artificial dyes to achieve a wider range of colors and to render the dyes more stable to washing and general domestic use. From history the earliest dyed flax fibers was found in a prehistoric cave in the Republic of Georgia in the year 34,000 BC [1-2]. More evidence of textile dyeing was dated far back to the Neolithic period at the large Neolithic settlement of Çatalhöyük in southern Anatolia, where traces of red dyes, possibly gotten from ocher which is an iron oxide pigment obtained from muddy clay, were found then [3]. According to scholars, in China, dyeing with plants, barks, and insects has been traced back to be more than 5,000 years [4]. It was initially believe that dyeing comes from Sindh province in Pakistan, where a piece of cotton dyed with a vegetable dye was recovered from the archaeological site at Mohenjo-Daro (3rd millennium BCE)[5]. Different classes of dyes are used for different types of fiber and at different stages of the 
textile production process, from loose fibers through yarn and cloth to complete garments. Acrylic fibers are dyed with basic dyes, while nylon and protein fibers such as wool and silk are dyed with acid dyes, and polyester yarn is dyed with disperse dyes., while cotton is dyed with a range of dye types, including vat dyes, and modern synthetic reactive and direct dyes.

Nigeria as a country is an extraordinary social-engagement driven society with greater percentage of the over 160 million people of her populace are fans of aso-ebifr one social event or the other. However, while uniformity and consistency is a paramount factor in the choice of aso-ebimaterial, "the third largestadire market in Africa" [6] lacks the capacity to service the demand of her immediate nation thereby the country's spending on the purchase of aso-ebiare taken abroad in exchange for printed fabric, not without its attendant dwindling effect on the nation's gross domestic product (GDP). On this note the necessity of a standard, uniformed coloured textile cannot be over-emphasised been conscious of the fact that the industry is well over three decades yet, it has compete with the present material being used aso-ebi. According to [7] who asserted that the Nigerian textiles and Clothing Workers Union estimates 350,000 jobs have been lost directly and 1.5 million indirectly over the last five years of Chinese competition. It must be a clarion call for us that the continual survival and expansion of our technical and artistic heritage of the products of our dyed fabrics is necessary by making an excellent and affordable dyeing machine. In Nigeria, Abeokuta is an age-long trade centre of tie-dye fabric which has employed women for centuries coupled with various stakeholders in the business and tourism sphere traversing the South-western State of Ogun's capital. Dyeing being an ancient art, it is often done manually giving results based on the dexterity of the artist and aesthetic application of colours, however due to industrial revolution, development in textile dyeing which has given us varieties of artificial dyestuffs is neck-to-neck with the advancement in machinery use thereby meeting the growing demands of speed, volume and exactness of production, but most of this equipments are expensive, making a most small scale and medium scale industries not to be able to afford this.

\subsection{OBJECTIVE OF THE RESEARCH WORK}

To design and construct:

- To fabricate a repromaster dyeing machine using locally sorted materials.
- To produce a fabric dyeing machine with optimum efficiency.

- A machine that dye textile materials in a unique manner.

- To construct a textile dye machine with less operational skill and minimal and affordable cost.

- To produce a faster and durable textile dyeing machine for small scale and medium scale enterprises.

\subsection{SIGNIFICANCE AND BENEFITS OF THE REPROMASTER DYEING MACHINE}

The Adire and Kampala (Tie and dye) business in Abeokuta Ogun state in Nigeria provides substantial contribution to the economy in the form of income, employment generation and possibly foreign exchange generation [8]. An innovation such as this designed and locally fabricated repromaster dyeing machine will expand the frontiers of production of such artistic pieces with greater uniformity and consistent pattern making. Although, uneven uniformity has been a major hindrance to the use of adire as aso-ebrin in Nigeria where aso-ebi is always desirable for special occasions such as wedding, birthday, anniversaries of associations etc which currently employs imported printed fabrics thereby short-changing our indigenously produced fabrics. This machine will therefore serve as the needs of effective teaching and learning in academic studios while creating frontiers for expanded production to the cottage textile outfits in Abeokuta, Ogun State and Nigeria at large. This is buttressed by the fact that there will be reduced cost of production as well as time saving and also increases production volumes.

\subsection{METHODOLOGY}

The machine consists of a drum compartment which houses a roller with four arms, as the roller is driven by the connected motor, it moves the fabric through the injected hot dye solution from the dye solution compartment. Around the drum is a huge perforated cylinder with four doors that lift out from each arm while fabric materials are being loaded inside and shuts water-tight while roller is moving the fabric through the dye solution. A timer circuit terminates the operation after the set time of the rolling action which is dependent on the concentration of the dye solution and the type of fabric being processed. 


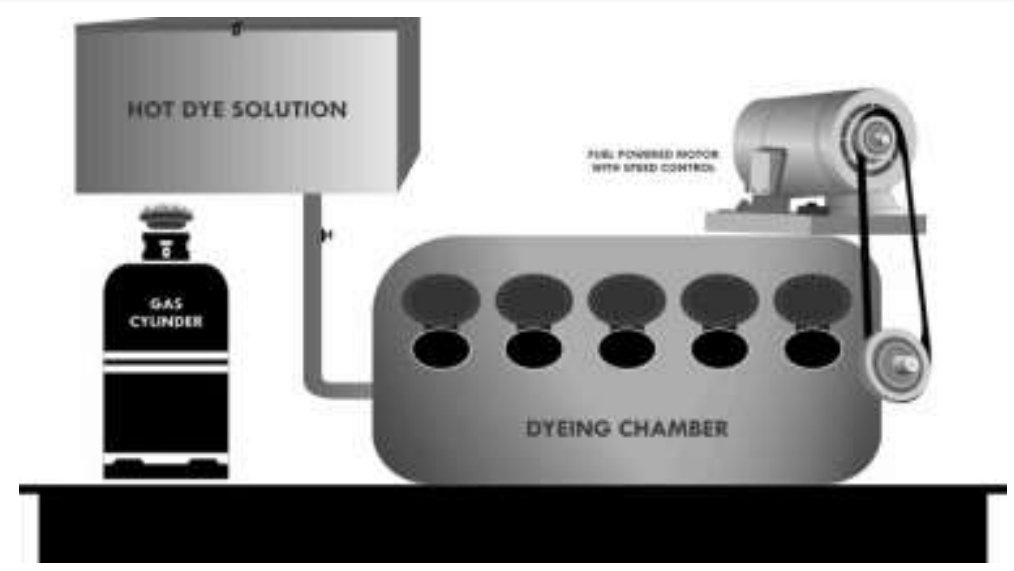

Figure 1: Process Diagram of Repromaster Dyeing Machine

\subsection{SELECTION OF DYEING METHOD}

Dyeing can be performed in three ways: exhaust or batch, semi-continuous and continuous method.

(1) Exhaust method is an optimum batch size is preferred as dyeing of several batches, may be in same machine, results variation in shade and hue for a given consignment. This method can be used for any form of textile: fibre, yarn or fabric.

(2) Semi-continuous methods are used for dyeing of longer length which should have same hue and shade throughout, examples of this is coarse fabrics, e.g. suiting, canvasses, etc.

(3) Continuous dyeing methods are to dye huge length of fabric in a uniform shade without any variation. This is done by padding followed by development or padding-drying- curing/steaming sequence. Dyes with good affinity are selected for exhaust dyeing whereas dyes with poor affinity are preferred for padding.

\subsection{REPROMASTER FIBRE DYEING MACHINE WORKING PRINCIPLE}

A perforated stainless steel rectangular container surrounds a central perforated hollow cylindrical tube and the container fits on a conical seating at the base of the tube (Shenai, 1993). The central tube is embedded with a high voltage heating element which provides the heated dye liquor and circulates it in an in-out mode for dyeing. A top cover with a lid is raised or lowered down to load and unload the machine (Figs. 2(a and b). The hot dye liquor coming from the heated rectangular container via the galvanized pipe was received by two conical lagged vessels which retained the hot water and the dye liquor temperature for proper dyeing before finally moved to the dyeing chamber which contain an impeller with a dye pattern mould which the textile has been already fastened together as shown in Figure 2a, then the outlet shaft was connected to the gasoline powered machine to provide a rotary motion to the patterned impeller for proper dyeing. The whole process system is done in a circular enclosed dye vessel chamber. The efficiency of the dyeing process depend on the machine speed.

\subsection{THE REPROMASTER TEXTILE DYE MACHINE CONSTRUCTION PROCEDURE}

(1) SCRIBING: This involves marking out the provided materials to be fabricated into the required specifications.

(2) CUTTING: This involving cutting either by sawing or using grinder to chop off materials to the required specifications. There is no way fabrication can be done without cutting either by sawing, grinding or use of gas to cut the metal to shapes and the desired pattern.

(3) GRINDING: This involved the use of electric grinder or pneumatic to chop off excess materials, it is highly essential during fabrication in order to ensure adequate smoothness and good surface finished.

(4) DRILLING: Drilling is a cutting process that uses a drill bit to cut a hole of circular cross-section in solid materials. The drill bit is usually a rotary cutting tool, often multi-point. The bit is pressed against the work-piece and rotated at rates from hundreds to thousands of revolutions per minute, any part that needed to be bolted or when there is need to couple two independent shaft together, we can drill, then bolted together.

(5). WELDING: This involve mating of two parts under high temperature, it may be by arc or by gas welding. During the fabrication, this two methods was adopted, gas welding was use to cut out the desired pattern of the dough mixer, and the electric arc welding machine was used to weld all the intricate and assembled parts together.

(6) PAINTING: This involves coating to prevent rusting and corrosion, it also adds to the beauty of the component, which makes it attractive.

(7) TEST-RUN: This involves pre-test of the fabricated components to see if the performance is up 
to the desired expectation, if it fails, further work will be done on it to ensure it works satisfactorily.

\subsection{REPROMASTER DYE MACHINE DESIGN DRAWING}

The figure 2(a and b) below show the exploded and front view drawing of the repromaster

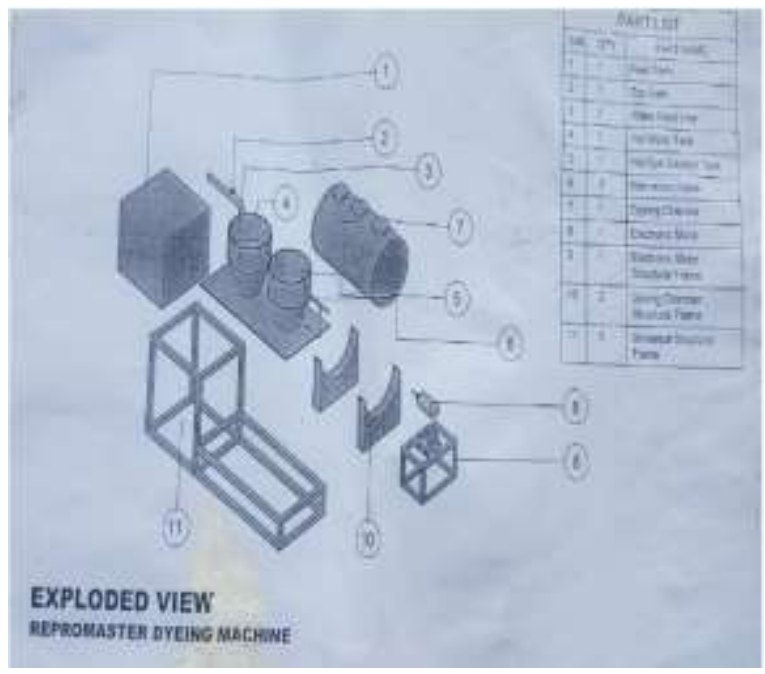

(a)

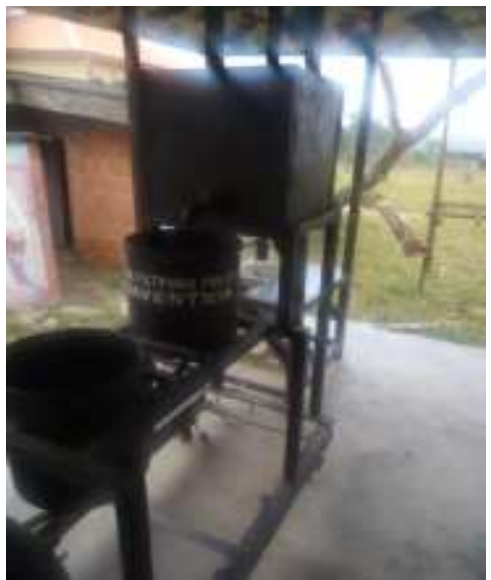

(a)

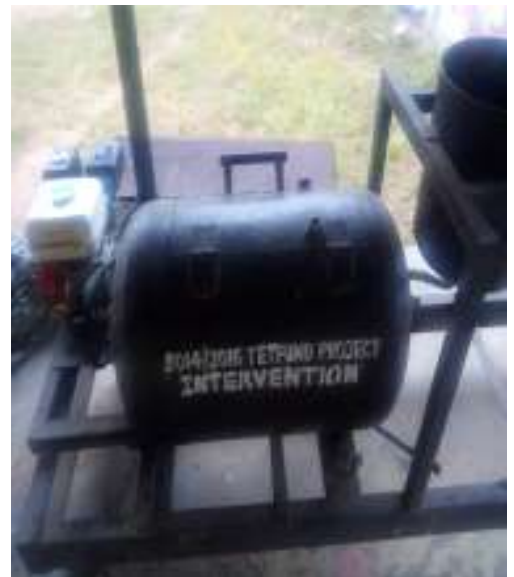

(b) dye machine and figure 3 also illustrate the pictorial view of the repromaster dye machine, the pictures in figure $3(a, b$ and $c)$ shows the pictorial view of the assembled machine as seen in figure $3 \mathrm{a}$, the figure $3 \mathrm{~b}$ and $3 \mathrm{c}$ shows the hot liquor dye mixing chamber and the interior of the chamber with a clear pattern of mould pattern as fixed to the impeller mixer shaft.

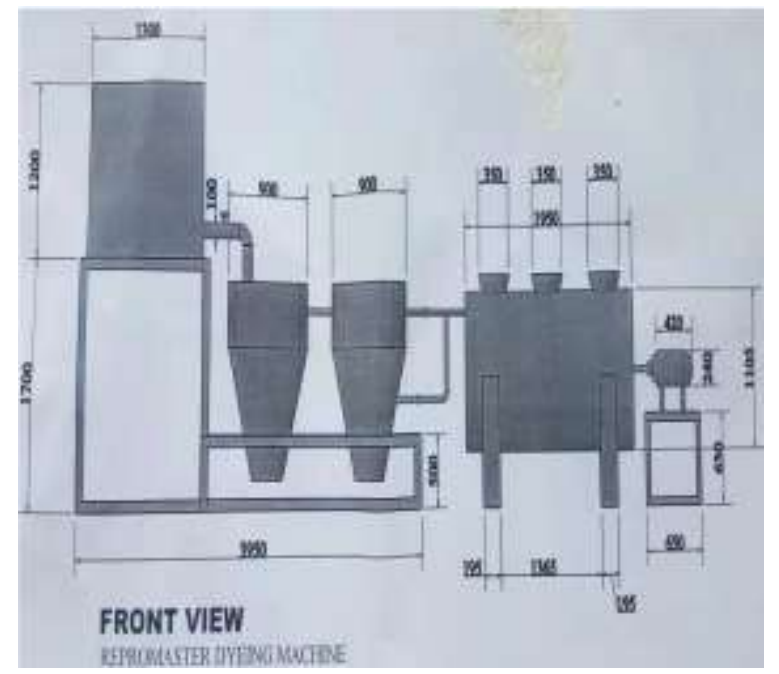

(b)

Figure 3 showing pictorial view of repromaster dye making machine The two types of pattern mould use for our textile dyeing during the test run is shown in figure 4(a and b). 


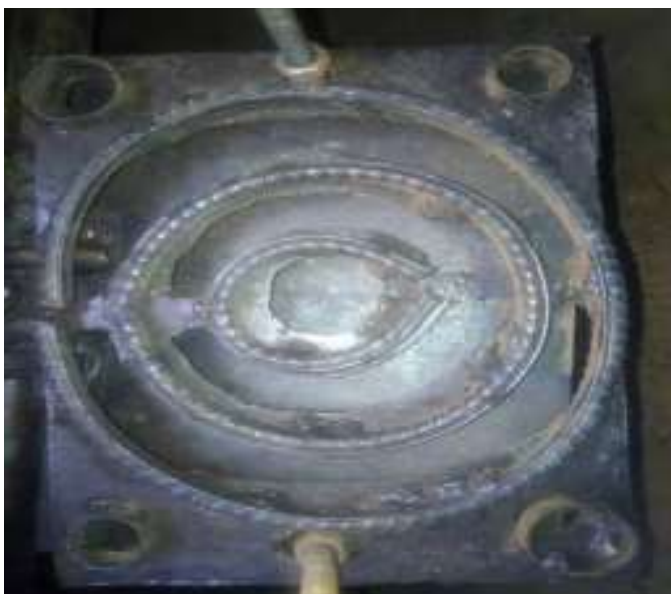

(a)

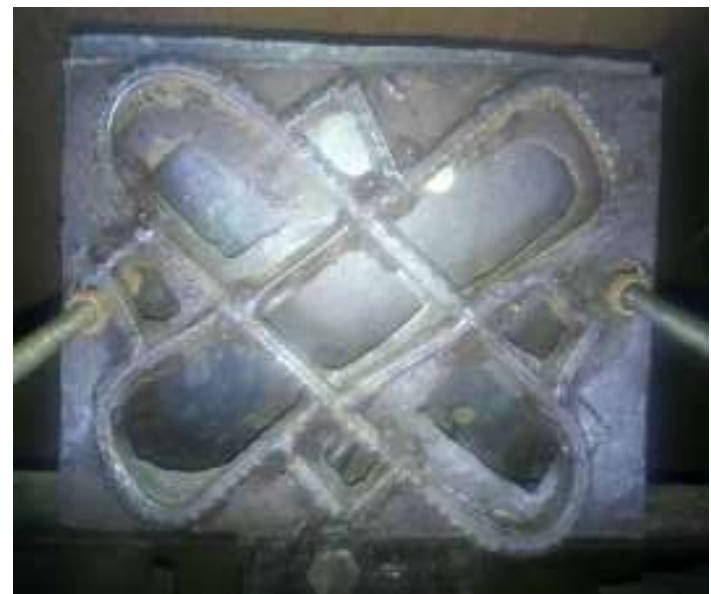

(b)

Figure 4(a and b) showing an example of mould pattern use in repromaster dyeing machine

\subsection{REPROMASTER MACHINE DESIGN CALCULATION}

\section{(a) Impeller Shaft Design}

The analysis of the shaft design formulas and modelling for our design are shown below, the detail analysis of the shaft diameter prior axial loading is determined by the formula:(Khurmi and Gupta,2003; Hall et al.,1983; Dixon and Poli,1995):

$\left.\left.d^{3}=\frac{16}{\pi \sigma_{s}} \sqrt{\left(K_{b}\right.} \cdot M_{b}\right)^{2}+\sqrt{\left(K_{t}\right.} \cdot M_{t}\right)^{2}$

Where, $\mathrm{d}=$ diameter of the shaft

$\mathrm{K}=$ the stiffness of the shaft

$\mathrm{M}=$ Torsion moment of the shaft

$M_{b}=$ Bending moment of the shaft $(\mathrm{N} / \mathrm{m})$

$M_{t}=$ Torsion moment of the shaft $(\mathrm{N} / \mathrm{m})$

$\sigma_{s}=$ Allowable shear and bending stress for the mild steel used in the construction.

The load caused by the dye liquor on the upper shaft is due to the weight of the two pattern mould on both sides and the gear and it is calculated to be $5.0 \mathrm{~kg}$.

$1 \mathrm{kgf}=1 \mathrm{~kg} \times 9.81 \mathrm{~m} / \mathrm{s}^{2}=9.81 \mathrm{kgm} / \mathrm{s}^{2}=9.81 \mathrm{~N}($ Khurmi and Gupta, 2005)

Weight of the gear $=36.30 \mathrm{~N}$

Mass of the impeller shaft was assumed using the density of the galvanized steel $=\left(7850 \mathrm{~kg} / \mathrm{m}^{3}\right)$.

Mass of the Impeller shaft $=4.09 \times 10^{-3} \mathrm{~kg} / \mathrm{mm}$.

Assuming sum of the clockwise rotation $=$ Sum of the Anticlockwise rotation .

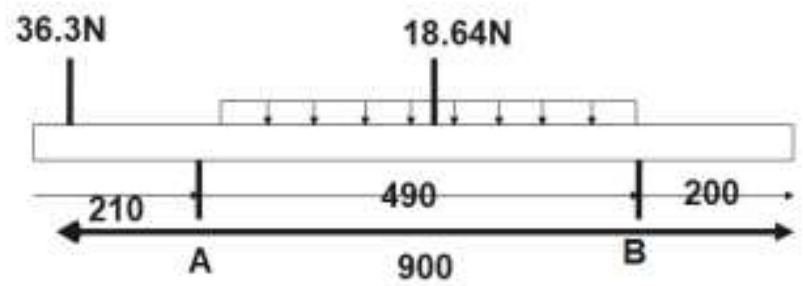

(a)

$R_{a}=61.18 \mathrm{~N}$ and $R_{b}=-6.24 \mathrm{~N}$

Maximum bending moment $M_{b}=7.62 \mathrm{Nm}$

\section{(b) Volume of Hot Dye Liquor Mixing Basin}

In designing an impeller for mixing 100 litres of dye liquor at assumed 5 inch $\mathrm{Hg} \quad\left(16942 \mathrm{~N} / \mathrm{m}^{2}\right)$, mixing pressure, $150 \mathrm{rpm}$ impeller speed, $1.15 \mathrm{~g} / \mathrm{cm}^{3}=\left(1150 \mathrm{~kg} / \mathrm{m}^{3}=\right)$ dye liquor density is the used volume calculation (Campbell, et al., 1993).

Dough volume, $V_{d}=\frac{m_{d}}{\rho_{d}}$

Where $V_{d}=$ dye liquor volume $\left(\mathrm{m}^{3}\right), m_{d}=$ colour blend mass $(\mathrm{kg})$ and $\rho_{d}=$ hot dye liquor density $\left(\mathrm{kg} / \mathrm{m}^{3}\right)$.

Dye liquor Volume $=\frac{10}{1150}=0.00869 \mathrm{~m}^{3}$

Assuming the volume of water + volume of air space + other added dye recipients $=30 \% V_{d}$. 
The volume of the mixing basin will then be;

$V_{d}=0.00869+(0.30 \times 0.00869)=0.00869+0.002607=\mathbf{0 . 0 1 1 2 9 7 \mathbf { m } ^ { 3 }}$

\section{(c) The diameter of Dye liquor mixing chamber}

This is determined with the empirical relationship given below:

Volume of mixing basin, $d_{d}=\sqrt{\frac{4 v_{b}}{\pi h_{b}}}$

Where $d_{d}$ is the diameter of hot dye liquor mixing basin (m), and $h_{b}$ height of mixing basin (m)

Let, $h_{b}=0.048 \mathrm{~m} ; d_{d}=\sqrt{\frac{4 v_{b}}{\pi h_{b}}}=\sqrt{\frac{4 \times 0.011297}{0.048}}=\sqrt{0.9414}=(0.9703)=970.3 \mathrm{~mm}$

(d) Power Requirement for the Gasoline Engine

The power which the gasoline fuelled must develop to drive the dye impeller mixer is determined with the expression by Khurmi and Gupta (2005).

$P=\frac{2 \pi N_{m} T_{m}}{60 \mathrm{\eta}}$

Where $\mathrm{P}=$ power developed by the gasoline motor,

$N_{m}=$ mixing speed (rpm),

$T_{m}=$ torque of the driven spindle shaft $(\mathrm{Nm})$,

$\mathrm{\eta}=$ efficiency of the reduction gear

Let, $N_{m}=150 \mathrm{rpm}, T_{m}=50 \mathrm{Nm}, \mathrm{\eta}=0.92$

$\mathrm{P}=P=\frac{2 \pi N_{m} T_{m}}{60 \mathrm{y}}=\frac{2 \times 3.142 \times 150 \times 50}{60 \times 0.92}=0.853 \mathrm{kw}(1.17 \mathrm{hp})$.

Therefore, the minimal power to drive the impeller shaft in the hot liquor mixing chamber must not less than $1.5 \mathrm{hp}$ with speed of $1440 \mathrm{rpm}$ is ideal.

\section{(e) Finite Element of the induction Heating Element}

The heating element provide adequate and controlled heating medium to the dye liquor for proper dyeing process. The heating element design calculation can then be deduced as the input is alternating current. The alternating current generates an alternating magnetic field in the coil which generates an induced electric field which in turn generates heat in the liquor basin. The electromagnetic field in the induction heating process is given by Maxwell's equations:

$\nabla \times \overline{\mathrm{H}}=\overline{\mathrm{J}}+\frac{\delta \overline{\mathrm{D}}}{\delta t}$
$\nabla \times \overline{\mathrm{E}}=\overline{\mathrm{J}}+\frac{\delta \overline{\mathrm{B}}}{\delta t}$

$\nabla \cdot \overline{\mathrm{B}}=\rho$

where $\overline{\mathrm{H}}$ is the magnetic field strength, is $\overline{\mathrm{J}}$ the conduction current density, $-\partial \partial \mathrm{t}$ is the displacement current density, $\mathrm{t}$ represents time, is the $\overline{\mathrm{E}}$ electric field, $\overline{\mathrm{B}}$ is the magnetic field, $\overline{\mathrm{D}}$ is the electric flux density, and $\rho$ is the volume charge density. The corresponding auxiliary equations are:

$\overline{\mathrm{D}}=\varepsilon \overline{\mathrm{E}}$

$\overline{\mathrm{B}}=\mu \overline{\mathrm{H}}$

$\overline{\mathrm{D}}=\sigma \overline{\mathrm{E}}$

where $\varepsilon$ represents the dielectric constant, $\mu$ is the magnetic permeability, and $\sigma$ is the electrical conductivity. The figure 5 ( $a$ and $b$ ) shows the simplification of heat source model and the position of experimental heat source.

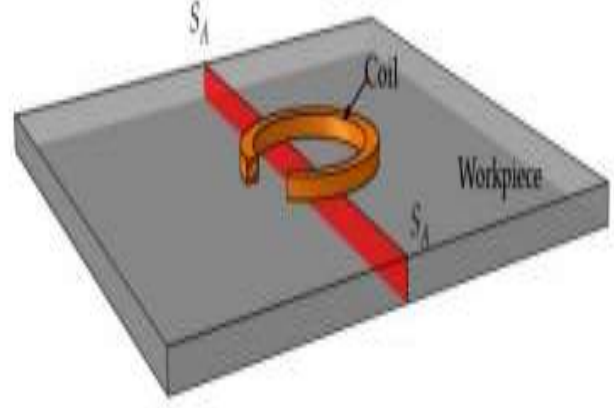

(a)

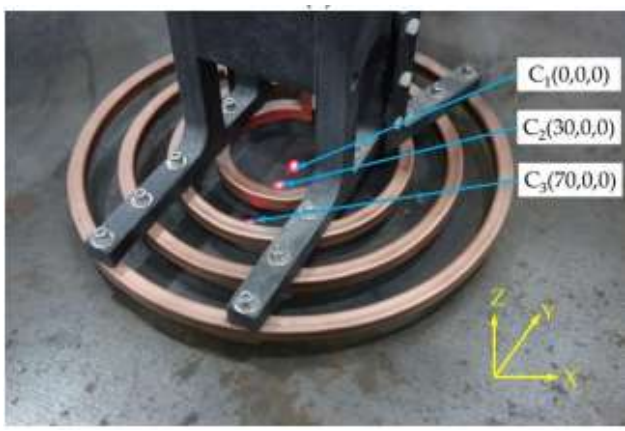

(b)

Figure 5(a and b) showing the model and ideal heating element of the heating basin 


\subsection{DYEING CALCULATION}

Dyeing RFT dyeing means "Right First Time Dyeing." This term is used to define the dyeing efficiency, if the efficiency is more than the dyeing capability of that company (mixture) is correct and accurate, otherwise not good an example of dye mixture is seen in figure 6 below. The term RFT actually defines how we can dye a fabric with our newly fabricated repromaster machine "If the dyeing process is completed properly without any fault \& there is no need to put the dyed fabric into the bath to get the proper shade then this dyeing is called RFT dyeing. Objective of RFT dyeing: i) Increase productivity: The productivity of a company can be increased if the RFT efficiency increased. ii) Reduce time consumption: If the dyeing completes in first time then it will take less time than the 2 nd time dyeing. iii) Increase profit: If the productivity increases then the profit will be increased too. iv) Less fabric damage: If the dyed fabric put 2nd time in a bath then there is a possibility to damage the fabric. v) Reduce cost. To get the RFT dyeing following problem may be effect the dyeing process. One of the main problem is to achieve the RFT Dyeing is the very little calculation variation of chemicals and dyes, the table 1 also show the dye recipe calculation used for our dye process. Without our knowledge we make mistakes during getting the chemicals analysis.

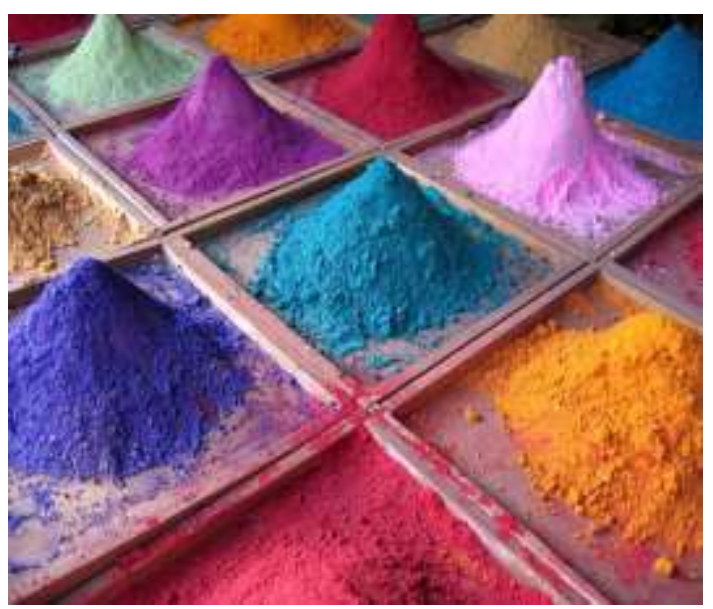

Figure 6 showing an example of dye recipe calculation used

Source: An Overview of Method Study in Apparel Industry, Retrieved from http://textilelearner.blogspot.com.ng/2015/12/types-of-dyeing-machine.html. 07:57pm, 17/03/2017.

Table 1 showing dye recipe calculation

\begin{tabular}{|c|c|}
\hline Chemical Name & Amount (kg/l) \\
\hline & 1 \\
\hline Phenolas D-250 (detergent) & 1 \\
\hline Novolute Jet (Anti-increasing agent) & 1 \\
\hline Fafstaring IR (Sequestering agent) & 0.4 \\
\hline Chimistab FG & 0.5 \\
\hline Piso OSR & 5 \\
\hline Soda ash & 2 \\
\hline Hydrogen Peroxide 50\% & 0.3 \\
\hline Catalese BF & 1 \\
\hline Acetic acid & 1.5 \\
\hline Phenolas CLN-20 & 0.5 \\
\hline Tex finish AL & 0.5 \\
\hline Gielev YDL & 1 \\
\hline Phenolas P-96 & 0.3 \\
\hline Eus Y sin-S & 1 \\
\hline Teracil-t & 0.5 \\
\hline Chimispere RK & 40 \\
\hline Glauber salt & 1 \\
\hline Faflev DBL & $1.5 \%$ \\
\hline Reactive Turquiose Blue G & $0.5 \%$ \\
\hline Reactive Yellow 4GL & \\
\hline & \\
\hline & \\
\hline
\end{tabular}




\subsection{OPERATING PROCEDURE}

- Take 50 litres water in the drum.

- Heat the water up to $80^{\circ} \mathrm{C}$.

- Now add dyeing chemical in drum and stir it well.

- Again heat the dyeing solution till temperature rise up to $80^{\circ} \mathrm{C}$ if any temperature drops.

- Now tie the cloths on the pattern mould on the impeller. Close the drum cover and rotate the supporting plate with motor.

- Continue the process up to $15 \mathrm{~min}$.

- Now open the drum cover and see that all cloths are dyed or not?

- Remove all colouring chemical from the drainage valve.
- Again close the drum cover and rotate the cloth for 15 mins after that open the drum cover and see those cloths little dried as water is thrown out by centrifugal force.

\subsection{RESULT AND DISCUSSION}

The experiment is carried out on plain white guinea cloth and one cotton shirt. By following procedure following observations were recorded shown in table 2 below. Time required as well as temperature drop was observed after the end of the dyeing process. Since time required dyeing the above clothes are reasonably short compared to manual dye system, it means the machine showed higher efficiency in terms of energy and time.

Table 2 Showing Performance Evaluation of Repromaster Dyeing Machine

\begin{tabular}{|c|c|c|c|c|c|}
\hline Item & $\begin{array}{c}\text { Time taken for } \\
\text { manual dyeing } \\
\text { (minutes) }\end{array}$ & $\begin{array}{c}\text { Time taken for } \\
\text { machine } \\
\text { dyeing } \\
\text { (minutes) }\end{array}$ & $\begin{array}{c}\text { Time saved } \\
\text { (minutes) }\end{array}$ & $\begin{array}{c}\text { Temperature at } \\
\text { the beginning of } \\
\text { test-run ( } \mathbf{}^{\circ} \text { ) }\end{array}$ & $\begin{array}{c}\text { Temperature } \\
\text { at the end of } \\
\text { test-run } \mathbf{(}^{\circ} \mathbf{C} \text { ) }\end{array}$ \\
\hline $\begin{array}{c}\text { guinea } \\
\text { cloth }\end{array}$ & $90-110$ & $35-40$ & 50 & 80 & 79.5 \\
\hline $\begin{array}{c}\text { one cotton } \\
\text { shirt }\end{array}$ & $80-100$ & $25-35$ & 55 & 80 & 79.2 \\
\hline
\end{tabular}

\subsection{CONCLUSION}

The performance analysis of Repromaster Dyeing machine was investigated and there is a substantial achievement in dyeing time and temperature drop. However, the repromaster dyeing machine design, construction and performance evaluation was successfully done. This can be afforded by small scale enterprises who are engaged in textile dyeing business because all the materials used for the design and construction was locally sourced. This machine provides an effortless cloth dyeing. In actual fact, this concept is innovative in textile industry and it is a brilliant idea towards improving dyeing process,

\section{SOURCES OF FUNDING}

This research is fully funded by Tertiary education trust fund grant (Tetfund 2016).

\section{CONFLICT OF INTEREST}

The author has declared that no competing interests exist.

\section{ACKNOWLEDGMENT}

I sincerely appreciate the immeasurable effort of $\mathrm{Mr}$ Akinlolu Olawale.O of the department of Industrial Art and design towards bringing a constructional idea and his wholly involvement in the fabrication process of this repromaster dyeing machine.

\section{REFERENCES}

1. Balter, $M$ (2009) "Clothes make the (Hu) Man". Science.325 (5946) :1329. doi:101126/science 325_1329a. PMID19745126.

2. Kvavadze, E; Bar-Yosef, $O$; Belfer-Cohen, A; Boaretto, E; Jakeli, N; Matskevich, Z; Meshveliani,T (2009). "30,000-year-old wild flax fibers" (PDF). Science. 325 (5946):

3. Barber, (1991), pp. 223-225.

4. Goodwin, Jill (1982). A Dyer's Manual. Pelham. ISBN 978-0-7207-1327-5.

5. Bhardwaj, H.C. \& Jain, K.K., "Indian Dyes and Industry During 18th-19th Century", Indian Journal of History of Science $17(11)$ : 70 81, New Delhi: Indian National Science Academy.

6. Kashim, I. B, Adiji B. E. and Oladunmiye E. B (2012): The Impact of Textile Industries on Students' of Textile Designs in Tertiary Instituions in South Western Nigeria. Education Research Journal.Vol 2 (3), pp. 75-86, March 2012.

7. Chiahemen J. (2006): Tsunami of Cheap Goods Overwhelms African Jobs. The New Zealand Herald. Available at http://www.nzherald.co.nz/category/print.cfm? $i d$,

8. Oloyede, A. M., O. Ogunlaja and A. Ogunlaja (2014): Sub-Chronic Toxicity Assessment of Local Textile Adire and Kampala (Tie and Dye) Effluents on Mice (Musmusculus). Research Journal of Environmental Sciences, 8: 142-143. 